\title{
'A escandalosa política grega da Europa' no debate entre individualistas e comunitaristas
}

\author{
'Europe's scandalous Greek politics' within the debate \\ between individualists and communitarians
}

\begin{abstract}
Henrique Raskin*
Resumo: O presente trabalho busca estabelecer um vínculo entre o artigo publicado por Jürgen Habermas no jornal Le Monde, em 25 de junho de 2015, intitulado 'A escandalosa política grega da Europa' com sua consagrada obra, publicada em 1981, chamada Teoria do Agir Comunicativo. Para tanto, este texto insere a publicação sobre a crise europeia no debate contemporâneo entre individualistas e comunitaristas, constituindo um diálogo entre perspectivas diversas, presentes na obra de Hannah Arendt, de filósofos liberais e de outros denominados de comunitaristas, como Rousseau, Hegel e Marx. Por fim, mostra-se que o texto de Habermas do Le Monde é permeado por sua teoria social que estabelece uma relação entre o mundo da vida e os subsistemas da economia e da política. Contrário à perspectiva anti-modernista de Arendt, e à proposta de restrição conversacional presente na tradição liberal, que institui limites à natureza humana, Habermas tem claro que o problema da crise é institucional. Por isso, condena o modelo político que a União Europeia tem adotado, ao concebê-lo distinto da ética conversativa já trabalhada em sua obra. Dessa forma, são trabalhadas no artigo as diferentes concepções que buscam caracterizar o construto político de uma sociedade democrática, utilizando o artigo de Habermas, recentemente publicado, como a base de uma discussão central da contemporaneidade.

Palavras chave: Ética conversativa. Teoria Crítica. Democracia. Crise europeia.

Abstract: This paper seeks to establish a link between Jürgen Habermas's published article in June $25^{\text {th }}, 2015$, at the newspaper Le Monde, called 'Europe's scandalous Greek politics', and his consecrated work, published in 1981, named The Theory of Communicative Action. Therefore, this paper inserts the publication about the European crisis within the contemporary debate between individualists and communitarians, constituting a dialogue among diverse
\end{abstract}

*Professor substituto da Universidade Federal do Pampa (UNIPAMPA). 
perspectives, present in the works of Hannah Arendt, of liberal philosophers and of communitarians, as Rousseau, Hegel and Marx. Lastly, it is shown that Habermas's Le Monde article is permeated by his social theory, which establishes a relation between the lifeworld and the subsystems of the economy and politics. Contrary to Arendt's anti-modernist perspective, and to the conversational restriction proposed by the liberal tradition, which launches limits to human nature, Habermas has it clear that the crisis problem is institutional. Hence, he condemns the political model the European Union has adopted, as he conceives it distinct to the conversational ethics already discussed in his work.

Key words: Conversational ethics. Critical Theory. Democracy. European crisis.

\section{Introdução}

No dia 25 de junho de 2015, Jürgen Habermas teve publicado no jornal francês Le Monde seu artigo 'A escandalosa política grega da Europa', em que criticou a maneira com que se tem lidado na Europa com a questão da dívida grega. Para fins político-informativos, o âmago da questão tem em si um conflito que expõe as diferentes implicações ético-governamentais entre os Estados do sul e do norte do continente europeu. Entre- diretamente envolvidos na questão tanto, filosoficamente, podem ser fiscal do país meridional, não apeencontrados nas entrelinhas do ar- nas estaria aplicando sua teoria do tigo de Habermas elementos do agir comunicativo, como também debate, que transcende o conflito estaria condenando as chances de grego, e que, em muito, pauta os trunfo que uma política com fundesafios da filosofia política con- damentos liberais poderia vir a ter. temporânea. Habermas, no artigo Assim, esse trabalho busca apondo jornal francês, expõe sua posi- tar os fragmentos do artigo do filó-

ção comunitarista ao passo em que questiona a efetividade de políticas sustentadas por concepções herdadas da escola liberal.

É, dentre o conflito entre o individualismo e o comunitarismo, que esse trabalho busca situar a Teoria do Agir Comunicativo de Habermas, ao identificá-la no artigo produzido pelo filósofo sobre a crise política europeia no Le Monde. Habermas, ao explorar as possibilidades do futuro da Grécia e ao interpretar as relações entre os Estados agir comunicativo, como tambem Assim, esse trabalho busca apon-
tar os fragmentos do artigo do filó- 
sofo no Le Monde que se mostram de acordo com a sua bibliografia filosófica, bem como visa a situar a questão discutida no embate entre individualistas e comunitaristas.

Para isso, pode-se observar a divisão desse artigo em três seções. A primeira, "Habermas e 'A escandalosa política grega da Europa'”, analisará o artigo publicado no Le Monde, situando-o na crise europeia, ao apresentar possíveis rumos políticos que a Grécia pode tomar. A segunda seção, "Individualismo versus Comunitarismo", apontará diferenças substanciais sobre as relações humanas em diferentes concepções sobre o indivíduo e o espaço público. E, por fim, a terceira seção, "Mundo da vida, sistema e democracia", recuperará os conceitos habermasianos de mundo da vida e sistema, demonstrando que eles se fazem presentes na ideia de ética conversativa da democracia.

Habermas e 'A escandalosa política grega da Europa'

Atualmente, o problema financeiro da Grécia tem se tornado o centro das preocupações políti- cas e econômicas que concernem o grupo de países PIIGS (sigla em inglês que designa os países europeus Portugal, Itália, Irlanda, Grécia e Espanha, com grandes endividamento e déficit público em relação a seus PIB). Contudo, o problema pelo qual passa a Grécia não é tão recente, podendo ele ser traçado desde os anos 2000, ao menos, quando a Grécia ingressou à zona do euro, de acordo com o jornal Business Insider UK. Um ano após a adoção do euro pela União Europeia, a Grécia também o definia como sua moeda oficial, mesmo sem apresentar as condições necessárias estabelecidas pelo bloco econômico: já nesse ano de 2000, o déficit público grego excedia a margem limite de $3 \%$ do PIB, e continuamente crescendo, chegou em 2009, aos níveis de $15 \%$, falsamente maquiados pelo governo como $6 \%$. Os títulos de dívida, cujos preços consequentemente despencavam no mercado, fizeram com que a Grécia aderisse, em 2010, ao resgate de 110 bilhões de euros do Fundo Monetário Internacional, em conjunto com o Banco Central Europeu e com a Comissão Europeia, entrando, a partir de então, em depressão econô- 
mica. Seu PIB, que diminuía $25 \%$ uma parcela do empréstimo do em relação ao ano anterior, tinha FMI no valor de 1,6 bilhão, apeem decorrência disso uma equi- sar de ter solicitado a membros da valente taxa de jovens desempre- zona do euro que fornecessem emgados, e também não apresentava préstimos à Grécia para permitir indícios de recuperação no curto renegociações com o FMI. A chanprazo, pois as reformas econômicas celer Angela Merkel, da Alemaimpostas como condição do resgate nha, disse, contudo, que "nenhum eram austeras e estranhas à reali- acordo com o governo do Sr. Tsidade da Grécia até então².

pras poderia ser negociado até o

Em 2012, a situação se agrareferendo agendado para domingo, vava, enquanto a Grécia recebia o resgate de mais 130 bilhões, aprovado pelo Pasok, partido de centroesquerda que detinha mais de $50 \%$ dos assentos no parlamento. Como reação à série de imposições econômicas que se somavam aos empréstimos, o partido de centro-direita New Democracy vencia duas eleições no parlamento, ao mesmo tempo em que o Syriza, coligação de extrema-esquerda, multiplicava por cinco sua presença no parlamento, a ponto de ganhar as eleições parlamentares em janeiro de $2015^{3}$.

Em junho de 2015, o primeiro mento da parcela de 1,6 bilhão ao ministro Alexis Tsipras, líder da FMI. Junto a isso, os bancos opecoligação de extrema-esquerda, rantes na Grécia expunham que perdeu o prazo de devolução de não haveria mais dinheiro a em-

\footnotetext{
2 Bird, 2015.

3 Bird, 2015.

4 NYTIMES, 2015, s/p, tradução nossa.
} 
prestar, surgindo, assim, o questionamento sobre a continuidade da Grécia na zona do euro ${ }^{5}$.

Das diversas possibilidades e repercussões independentes dos diferentes resultados do referendo, é fato que, saindo ou não a Grécia da zona do euro, tem-se um embate político sobre os rumos políticos do século XXI, transcendentes ao específico caso grego. Habermas $^{6}$, ao publicar o seu artigo 'A escandalosa política grega da $\mathrm{Eu}$ ropa', comprova, ainda que implicitamente, que a questão política da Grécia se eleva aos níveis filosóficos. Sobretudo, a atualização das correntes de pensamento político às questões do século XXI, mostra o quanto a teoria política pode auxiliar na compreensão e na resolução de conflitos práticos.

$\mathrm{O}$ artigo de Habermas no Le Monde aborda o caso grego, mas, mais do que isso, trata sobre a relação entre os cidadãos e as estruturas que os enquadram; ou, em termos habermasianos, sobre as relações entre o mundo da vida e os subsistemas da economia e da política, como será observado posteri- ormente. O que Habermas defende em seu artigo é que os rumos políticos que tem a Grécia manifestado nos últimos anos demonstram a insuficiência do modelo institucional da política europeia, frente às demandas da população do continente. Assim, o filósofo acusa que não pode mais a elite europeia se proteger através de seus eleitores, $\mathrm{o}$ que impede o florescimento de alternativas para a 'comunidade monetária politicamente inacabada', que hoje possui a última palavra; e defende, também, que a deliberação democrática se sobreponha às decisões dos banqueiros. Portanto, Habermas não visa a criticar a dicotomia Alemanha-Grécia no que diz respeito à relação credordevedor da dívida; o filósofo, sobretudo, ressalta a oposição que se apresenta entre o povo europeu e o vício de suas instituições que, supostamente, deveriam ser democráticas.

Para tanto, há genericamente cinco pontos abordados por Habermas em relação àquilo que ele chama de 'escandalosa política grega da Europa'. Ao que o filó-

\footnotetext{
${ }^{5}$ NYTIMES, 2015.

${ }^{6}$ Habermas, 2015.
} 
sofo alemão inaugura seu texto, ele sublinha que a eleição da extremaesquerda na Grécia significa per se a rejeição das políticas de austeridade como condição ao regate econômico. A ascensão ao poder do Syriza já se mostraria um reflexo de uma mudança de política na zona do euro, devido ao fracasso do modelo da austeridade. Como Habermas coloca: "Fortalecido da legitimação democrática, o governo grego tenta provocar uma mudança de política da zona do euro. Fazendo isso, ele enfrenta os representantes dos outros dezoito governos, que justificam suas recusas, referindo-se friamente aos seus próprios mandatos democráticos" 7 .

Em segundo lugar, Habermas aponta para a crise do modelo Estado-nação, ao conduzir as atenções do leitor à vontade popular que supera as delimitações nacionais. Habermas contrapõe, nesse sentido, o movimento popular que pôde eleger o Syriza na Grécia, e que cresce no continente como um todo, em relação aos "métodos tecnocráticos" permeados no sistema de representação que não mais permite a insurgência de uma "vontade política dos cidadãos". Sob a mesma lógica, o filósofo alemão aponta que, caso falhem as negociações entre credores e o governo grego, o motivo não seria os desentendimentos entre as partes, mas, sim, o "vício dos procedimentos e das instituições" que não se mostram de acordo com as novas demandas da população europeia. O filósofo observa, no movimento grego em relação à crise fiscal, o florescimento popular frente às elites corruptas da Europa, que vêm carregadas de um aparato institucional falido, que Habermas atribui às dificuldades de lidar com a crise fiscal grega. Ele acusa que, com a tecnocracia da União Europeia, mantém-se existindo a dívida, ainda que impagável para a Grécia. A perversão da tecnocracia é que, mesmo insuficientes e fictícias, as concessões feitas impedem que qualquer decisão seja tomada,

\footnotetext{
7 HABERMAS, 2015, s/p, tradução nossa.

${ }^{8}$ Cf. Habermas, 2015, s/p, tradução nossa: "A falha do compromisso não se dá por bilhões a mais ou a menos, nem mesmo por causa 'desta ou daquela' cláusula especifica, mas unicamente devido a uma reivindicação: os gregos demandam que seja permitido à sua economia e à sua população explorada por elites corruptas um novo começo, ao desconsiderar uma parte de seu passivo - ou estabelecendo uma medida equivalente como, por exemplo, uma moratória, sobre essa dívida, cuja duração dependa do crescimento".
} 
conservando a estrutura política da Europa, tal como ela é ${ }^{8}$.

Todavia, coerente à crítica da tecnocracia e da estrutura elitista de poder na Europa, Habermas não se reduz à condenação de apenas parte da política europeia, ao reprovar também a política moralizante que o próprio Syriza tem adotado. Habermas culpa a esquerda grega que, em vez de buscar penetrar a União Europeia com as alternativas que o povo grego vem discutindo, tem se reduzido ao clientelismo característico da região. Por isso, o filósofo teme que, no lugar da superação do modelo do Estado-nação, surja, em contrapartida, um nacionalismo de esquerda, que rejeite mais um resgate, e promova a rescisão do contrato da Grécia com o euro. Dessa forma, o Syriza, em vez de solucionar o problema fiscal da Grécia com alternativas internas à União Europeia, poderia acentuar a disputa nacional contra a administração central de Bruxelas e Berlim, reduzindo soluções políticas de superação da crise à simples cobrança dos resgates econômicos. Para Habermas, esse cenário só teria a prejudicar a situação, pois a irresponsabilidade do go- verno grego, de se posicionar mais como moralizador do que como solucionador, mascararia as relações de dominação econômica dos Estados mais fortes sobre os mais fracos como "questão de direito privado frente aos tribunais". Portanto, e por fim, Habermas salienta que o problema da 'escandalosa política grega da Europa' se mostra tanto entre os Estados líderes, quanto na Grécia. Se, por um lado, o Syriza pôde herdar o clientelismo tradicional, posicionando-se como agitador moral pela retirada da Grécia da zona do euro, por outro lado, líderes como Angela Merkel, ao adotar a posição de simples credora, isenta-se da responsabilidade sobre as consequências do afundamento grego em uma dívida pública cada vez maior. Habermas, então, remonta o seu desconforto em relação à colonização no mundo da vida pelos subsistemas, ao expressar que "o essencial não é a vergonha moral, mas o testemunho político: as elites políticas na Europa não têm mais o direito de se mascarar por trás de seus eleitores e de se esquivar de alternativas diante de uma comunidade monetária politicamente inacabada. São os cidadãos, não os 
banqueiros, que devem ter a úl- público ainda se mostram em muitima palavra sobre as questões do tos aspectos conflitantes, mesmo destino europeu" 9 .

após tentativas de conciliação; e, também, demonstrar que se pode identificar no diagnóstico haber-

Individualismo versus Comunitarismo

masiano da crise grega a parcialidade de elementos que remontam séculos de uma suposta perspec-

Habermas tem claro em seu artigo o problema que a Europa enfrenta nos dias de hoje: a tectiva comunitarista.

Seyla Benhabib, em Situanocracia 'representativa', que im- ting the Self: Gender, Community pede o florescimento de alternati- and Postmodernism in Contempovas clamadas pela população. En- rary Ethics ${ }^{10}$, propõe três modetretanto, se introduzidas no de- los de espaço público, que de uma bate sobre os rumos políticos as forma ou outra, se posicionam em históricas divergências filosóficas, meio ao debate do individualismo chega-se a um claro desacordo. En- com o comunitarismo. O nome do quanto para Habermas, o embate livro sugere, contudo, a corrente fique se tem na União Europeia hoje losófica que Benhabib identificaria é, principalmente, entre as forças em seus ideais de emancipação de tecnocráticas do status quo e as grupos historicamente excluídos. formas democráticas que buscam Sua afinidade com a ética discuralternativas a ele, pode-se enxer- siva de Habermas a conduz, porgar também no desacordo europeu tanto, a enxergar a desconexão enuma multiplicidade soluções polí- tre os modelos agonístico de Hanticas concorrentes, algumas advin- nah Arendt, liberal de Rawls e dedas da tradição do pensamento li- liberativo de Habermas, demonsberal, outras, do legado comunita- trando que, para suas intenções de rista. O objetivo dessa seção do ar- abordagem de gênero, o conceito tigo será, justamente, apontar que habermasiano seria o mais aproos diferentes modelos de espaço priado.

\footnotetext{
${ }^{9}$ Habermas, 2015, s/p, tradução nossa.

10 Benhabib, 1992.
} 
O primeiro endereçamento de Benhabib é para Arendt e para o que ela propõe como modelo de espaço agonístico. A Condição Humana, muitas vezes taxada de antimoderna, remonta o modelo grego da pólis antiga, onde a política era pautada pela individualidade, igualdade e liberdade daqueles que se enquadravam como cidadãos. Como principal característica, o espaço público agonístico de Arendt abraçava a competição entre seus agentes, pois servia como solução à futilidade da vida humana, na busca da imortalidade, por meio das ações e do discurso. Enquanto nesse modelo ateniense a participação política somente seria permitida àqueles que superassem as necessidades do lar, 'o advento moderno do social', das revoluções americana e francesa viria a preparar o terreno para o totalitarismo, que no século XX teria obtido a sua forma mais radical ${ }^{11}$.

$\mathrm{O}$ individualismo, extremamente caro a Arendt, enquanto alternativa ao 'advento do social', foi o núcleo das críticas de Benha- referência a pré-modernidade, Bebib. A primeira das críticas diz nhabib aponta que as condições

\footnotetext{
11 Arendt, 2010.

12 Benhabib, 1992.
}

respeito ao fato de que enaltecer a individualidade dos gregos poderia significar a negligência em relação a questões próprias da modernidade, que não poderiam ter existido no tempo da Grécia Antiga. Benhabib enfatiza que, para poder ter existido a individualidade do espaço agonístico, fora necessário que grande parte da população da pólis fosse excluída do espaço político. Mulheres, escravos, trabalhadores e estrangeiros não se enquadravam como cidadãos e, por isso, não faziam parte do sistema elitista que permitia espaço ao individualismo. Justamente, contra a tradição advinda disso, o advento do social na modernidade representou a emancipação desses grupos excluídos, que passaram a buscar espaço na política moderna ${ }^{12}$.

Mesmo que Arendt apenas buscasse na Grécia Antiga um norteamento para a recuperação da virtude na modernidade, ou que tentasse estabelecer uma relação entre modernidade e totalitarismo, tendo como 
que permitiam a existência de reclusos no lar da pólis passaram um espaço agonístico individua- a ser objeto da emancipação deslista eram opostas às circunstân- ses grupos historicamente excluícias que pautam o mundo mo- dos até as revoluções liberais do séderno associativo, ao qual Arendt culo XVIII. Se, para Benhabib, denota as sementes do fascismo. o individualismo de Arendt podeDe acordo com Benhabib, a pó- ria vir a ser sinônimo de elitismo e lis grega possuía uma comunidade moralmente homogênea, com uma política igualitarista, embora exantimodernismo, o conceito de espaço público desenvolvido pela filósofa de A Condição Humana tamclusiva a uma pequena minoria, bém não poderia satisfazer os desaonde a ação (léxica e prática) reve- fios da contemporaneidade, ao não lava o self do agente político (cida- os contemplar. A confusão entre dão), em uma competição pela ex- ação, obra e trabalho na modernicelência. Já no modelo moderno dade não seria eficaz para selecioassociativo, tem-se uma comunidade eticamente heterogênea, em que se apresentam relações assimétricas de poder, que, embora injustas, incluem todos os componentes de uma determinada sociedade. Dado esse contexto, a ação só poderá ter repercussão quando coletiva, onde os agentes sejam anônimos, por apenas pertencerem a uma 'massa' populacional; a competição, que na Grécia Antiga era em busca do destaque, na modernidade visaria à justiça social; e o que na pólis grega pertencia à esfera do lar (a família, o trabalho e o comportamento), na modernidade encontrou espaço na esfera política, pois esses elementos nar na esfera privada os poucos cidadãos "dignos de cidadania". Por outro lado, a supressão do individualismo no associativismo de Arendt era, por demasiado, focada na insurgência da temática 'poder' nesse coletivo, o que para Benhabib e Habermas também não é o que o que está em jogo. Benhabib visava a mostrar que o que é central na política contemporânea é o diálogo, independentemente de seu objeto - seja a ação individual, seja o poder coletivo. O que importa, para eles, é o procedimento conversacional. Por isso, ela dirige também suas críticas à tradição liberal, que supostamente buscaria a 
restringi-lo ${ }^{13}$.

As primeiras obras da tradição liberal surgiram no século XVII, em publicações de John Locke que buscavam combater o absolutismo e a tirania, ao mesmo tempo em que visavam a alcançar a paz em meio aos conflitos religiosos de sua época. Assim, a semente da tradição liberal seria a elaboração de uma ordem política justa, estável e tolerante, assegurada pelas instituições e agências públicas ${ }^{14}$. É mister ressaltar que, em Hobbes, que já desenvolvia ideias liberais, havia um rompimento com o modelo grego da pólis antiga: o liberalismo, que possui como cerne o individualismo, o teve de forma diferente do modelo agonístico. O Leviatã de Hobbes rompia com Aristóteles ao estabelecer uma concepção atomística dos indivíduos em movimento, atestando igualdade e liberdade entre todos os homens, e concebendo o Estado como uma construção artificial.

O individualismo, na tradição liberal, possui um significado diferente do individualismo do modelo agonístico de Arendt, mas ainda não satisfaz Benhabib enquanto modelo legitimamente democrático, por ela contestar a restrição conversacional de Ackerman e Rawls. No espaço agonístico grego, permeado pela disputa, o individualismo era algo a ser alcançado politicamente: a natureza competitiva caracterizava e enriquecia a política grega. Já no modelo liberal, o individualismo é o ponto de partida, cujas consequências deverão ser corrigidas pelo Estado moderno. Assim, tem-se, já em Hobbes, a finalidade do Estado de retirar o homem de sua natureza, da mesma forma com que Locke irá suprimir o estado de guerra e com que Kant subordinará as vontades naturais à razão. Para Benhabib, a restrição conversacional dos liberais contemporâneos vem a remontar essa poda dos indivíduos, com vistas a evitar desacordos dentre contextos políticos eticamente diversos. Assim, ela endereça suas críticas ao que julga insuficiente na tradição liberal, focando principalmente em dois aspectos: primeiro, no caráter autoritário da restrição conversacional,

\footnotetext{
13 Benhabib, 1992.

14 Benhabib, 1992.
} 
e segundo, no papel passivo da ra- rado, para Habermas, esse ponto zão pública, enquanto apenas um de partida é equivocado, pois nas 'corpo investigativo parlamentar', relações intersubjetivas, permeae não ator direto na construção do das pela comunicação, é que podebate público ${ }^{15}$.

A filósofa critica, primeiramente, o fato de a tradição liberal pressupor que os grupos éticos em uma sociedade já sabem de antemão no que divergem entre si. Não somente, na concepção liberal, eles devem também ter clara a distinção entre o que é ético e o que é politicamente razoável, antes de adentrarem ao debate público. A primeira acusação de Benhabib se dá em relação a essa concepção de que, antes do relacionamento em sociedade, já se têm estabelecidas tanto as pautas de discussão, quanto a diferenciação entre público e privado, e os posicionamentos que cada indivíduo terá enquanto pertencente à sua comunidade ética. $\mathrm{O}$ individualismo da tradição liberal permitiria esse tipo de abordagem, pois tem na oposição sujeito-objeto um indivíduo impediria mudanças em uma sociautorreferenciado. Para Benhabib, edade, pois ela serviria à manutene, como posteriormente será explo- ção do status quo, tanto nas rela-

\footnotetext{
${ }^{15}$ Benhabib, 1992.

${ }^{16}$ Para isso, Benhabib cita o caso da divisão sexual de trabalho, por exemplo, que poderia ser impedido de adentrar ao debate público, dado o desacordo em torno do tema. Argumenta, assim, que as questões trabalhistas, antes do Estado de bem-estar social, eram consideradas 'privacidade dos negócios', não contemplando o espaço
} 
ções hierárquicas, quanto comportamentos socialmente aceitos ou não ${ }^{16}$.

Assim, Benhabib enxerga no 'véu da ignorância' a opressão do pragmatismo, onde, para se pensar em uma situação ideal de justiça, deve-se, obrigatoriamente, despirse de sua realidade ética e compreender uma igualdade que, na realidade, não existe. Sob esse discurso, Benhabib acusa que, sob o véu, não seria permitido aos grupos marginalizados utilizar sua condição subjugada para transformar a realidade social: para ela, no modelo liberal, não há espaço para os movimentos feminista, pacifista, ecológico ou de identidade étnica, pois, pela restrição conversacional, eles deveriam se contentar com a discussão na esfera privada, e não pública. Dessa forma, não poderiam penetrar a política, ao não comporem a ideia de consenso sobreposto. $\mathrm{O}$ individualismo do liberalismo não permiti- por outros" ${ }^{18}$. A comunidade, ria a emergência dos 'selves coleti- aqui, não possui apenas papel senvos', pois para os filósofos da tradi- timental no indivíduo; ela constição, o que importa é o indivíduo, tui, sobretudo, as identidades pesdissociado das possíveis comuni- soais.

\footnotetext{
público, por não serem consideradas questão de interesse público.

17 Benhabib, 1992.

18 Forst, 2010, p. 20.
} 
Por isso, ao passo em que co- mística", compõe a tradição comumunitarismo se desenvolvia na tra- nitarista, que principalmente desdição filosófica, ele passava a re- cende de Rousseau, Hegel e Marx. jeitar o contratualismo que forte- Dessa forma, o filósofo alemão desmente se manteve na tradição li- loca o foco sobre o indivíduo, obberal. Rousseau, quiçá o primeiro servando mais enfaticamente as recomunitarista da modernidade, já lações 'orgânicas' entre eles, que enxergava no contrato social a re- não em forma de contrato comnúncia ao recolhimento da vida põem uma determinada sociedade privada; seu republicanismo exigia política. A Teoria do Agir Comunique o indivíduo vestisse o traje pú- cativo, mais notável obra do penblico do cidadão, a compor a von- sador, dialoga diretamente com a tade geral, ainda que contratual- teoria social, demonstrando que a mente $^{19}$. Entretanto, somente He- filosofia não se descola da histógel romperá com o modelo con- ria da sociedade e tampouco de tratualista de compreensão do Es- sua condição social dos homens. tado moderno, ao recuperar a con- No desenvolvimento dessa obra, cepção gregária do zōon politikon, Habermas se apropria de modelos inserindo-a nos tempos modernos hegelianos, marxianos, e weberiado advento do social. Hegel ad- nos, dentre muitos outros, e com mitia entender o homem como eti- isso apresenta o modelo que comcamente constituído, sem conce- bina o mundo da vida fenomenober sua existência como anterior a lógico com os subsistemas da ecoqualquer 'acordo' político. $\mathrm{O}$ indivíduo em Hegel remonta o indivíduo helênico, mas, nem por isso, o espaço público de Hegel se pautou pelo agonismo e individualismo competitivo que Arendt atestou.

Habermas, em oposição ao connomia e política, distinta e separadamente. Essa abordagem hermenêutica mostrará uma alternativa para a proposta liberal, principalmente, trazendo em seu procedimentalismo um caráter democrático que o liberalismo é acusado de não conter.

tratualismo e à perspectiva "ato-

${ }^{19}$ Rousseau, 1973. 
Mundo da vida, subsistema e democracia

Habermas é claro sobre onde quer chegar com A escandalosa política grega da Europa. Seu alvo é evidente: o institucionalismo tecnocrático europeu que, por estar viciado, não permite que surjam alternativas populares ao modelo fracassado da zona do euro, como demonstra a Grécia do Syriza. Para isso, deve-se ter em mente que Habermas, na Teoria do Agir Comunicativo, direciona seus esforços a criticar a razão funcionalista, presente nas teorias sociais de Durkheim, Parsons e Luhmann. O filósofo, cujo objeto de análise veio a ser a ação humana, passou a rejeitar perspectivas que interpretavam a sociedade enquanto sistemas funcionais, análogos a organismos vivos, bem como estruturas de produção, como Marx associava infraestrutura com superestrutura, onde o indivíduo enquanto agente não tinha espaço relevante. Também, a Habermas não servia o behaviorismo, pois nessa escola não havia espaço para a autonomia dos indivíduos, que agiam apenas pelo condicionamento do prazer e da dor. A ação humana, que Ha- bermas enfoca, tem em si um caráter racionalizado, já explorado por Weber; no entanto, ele não apenas descreve a racionalidade moderna com base em seu desenvolvimento histórico; há, sobretudo, na ética conversativa, um poder normativo imanente às relações intersubjetivas, o qual ele herda de Hegel. No entanto, o procedimentalismo kantiano, bem como a concepção marxiana trágica das relações de produção, conferem a Habermas um modelo dualista de sociedade, onde cabem o conceito de mundo da vida e uma teoria de sistemas, que se diferenciam de uma esfera hegelianamente 'orgânica' das relações intersubjetivas.

Nesse contexto, Habermas permite que os atores sociais encontrem objetividade (com as entidades efetivamente estabelecidas em sociedade), normatividade (por meio da regulamentação das relações interpessoais) e subjetividade (a partir das vivências individuais de cada agente social) no mundo da vida. Por outro lado, Habermas enfoca também na diferenciação dos sistemas, que surgem internamente ao mundo da vida, porém adquirem uma independência 'deslingüistificada', que 
se exterioriza em relação à ética mentos dessa tradição, sobretudo conversativa. Esse fenômeno, su- de Hegel, Marx e Weber. Em Hejeito à evolução social, remonta- gel, pode-se notar como cerne de ria uma racionalização das cons- sua filosofia política a suprassuntruções linguísticas, "atingindo um ção da família, na sociedade civilponto em que os imperativos do burguesa, e então no Estado, onde sistema, libertos, detonam a ca- se conservam elementos de suas pacidade hermenêutica do mundo etapas constitutivas, sendo cada da vida, instrumentalizando-o" ${ }^{20}$. uma delas momentos de uma toCom isso, Habermas estabelece talidade ética. Habermas recupera que, interiormente ao mundo in- essa noção de imanência ética, ao tersubjetivo de representação da compreender que, mesmo externarealidade e de normatividade ética, dos do mundo da vida, os subsisteos sistemas da economia e da polí- mas da economia e da política não tica viriam a se formar, suprimindo a linguagem enquanto seu meio de sustentação exterior. $\mathrm{O}$ sistema econômico passa a ter sua própria 'linguagem', o dinheiro, bem como o sistema político passa a operar sob a referência do poder. Os sistemas tornam-se, assim, autopoiéticos.

Entretanto, essa concepção 'caíram do céu'.

Contrariando a perspectiva funcionalista de Durkheim, Habermas identifica no processo de evolução social a formação dos subsistemas que, por exemplo, viriam a introduzir a divisão social do trabalho nas relações intersubjetivas, não necessariamente naturais ou orgânicas na sociedade. Sob a dual, embora diferenciadora, não divisão de seu modelo social em mostra uma dissociação completa mundo da vida, economia e poentre o mundo da vida e os siste- lítica, Habermas se apoia na vimas da economia e da política, que são weberiana de que os indivíinfluem um no outro, provocando duos agem com base na cultura, transformações. Nesse aspecto, na economia e na política. Já pode-se traçar o aspecto comunita- em A Ética Protestante e o Espírito rista de Habermas, que herda ele- do Capitalismo, Weber demonstra

20 Habermas, 2012, p. 281. 
como a observação da ação racional dos indivíduos, econômica e política, pode ser explicada pela cultura, no caso, religiosa. Essa tríade cultura-economia-política seria reproduzida por Habermas na Teoria do Agir Comunicativo, ao expor a complexidade dos sistemas econômico e político, originados dentro do mundo da vida, de forma compartilhada.

Porém, vê-se, nessa crítica, que Habermas adquiriu também elementos marxianos, fortemente presentes na Escola de Frankfurt, de que faz parte. A dualidade entre superestrutura e infraestrutura, onde uma sustenta a outra, é apropriada em Habermas através do movimento de colonização dos subsistemas na esfera do mundo da vida, que se legitimam em sociedade por meio da adoção do dinheiro e do poder enquanto mediadores das relações intersubjetivas. É com base nesse entendimento que Habermas descreve o processo da estratificação. Ao analisar a sociedade moderna, por exemplo, o filósofo explica o sistema econômico capitalista, como consequência do dinheiro "que cons- titui um novo mecanismo de controle". Ele continua: "Tal meio se especializa na função da atividade econômica da sociedade global, cedida pelo Estado, formando a base para um subsistema que se emancipa dos contextos normativos"21. Assim, Habermas transforma o modelo 'superestrutura/infraestrutura' em um modelo 'mundo da vida/subsistemas', onde a base precisa da ideologia, ou da legitimação do mundo da vida, para sua sustentação. Sem elas, não poderiam existir nem as relações de produção, para Marx, nem os subsistemas de Habermas.

Essa breve descrição da relação do mundo da vida com os sistemas autopoiéticos, ao menos mostra como Habermas se insere dentro de uma tradição comunitarista da filosofia, separandoo de outras perspectivas, como a individualista-atomista, que possui grande influência na história da filosofia. Visando esse debate, Benhabib comenta a ética discursiva:

O significado de participação é alterado [no contexto discursivo]. O foco exclusivo na participação 'política' desloca-se em direção a

\footnotetext{
${ }^{21}$ Habermas, 2012, p. 309.
} 
um conceito muito mais inclusivo da 'formação da vontade discursiva'. A participação não é vista como uma atividade que é apenas e tão somente possível em uma esfera política estritamente definida, mas como uma atividade que também pode ser realizada na esfera social-cultural $^{22}$.

Benhabib, não muito diferente de Habermas, encontra na ética discursiva uma solução para o debate entre a vontade da maioria e as garantias constitucionais 'indiscutíveis'. Entretanto, deve-se ter atento que esse procedimentalismo conversativo de Habermas tem como meta o diálogo normativo como uma conversa de justificação - frente ao agonismo elitista dos helênicos e ao liberalismo da normatividade imediata. Se para os liberais, há garantias constitucionais (como liberdades individuais e o direito à propriedade privada) que jamais poderiam ser questionadas, por garantirem a ordem e a estabilidade em uma sociedade plural, na ética conversativa eles estão sujeitos, pelo menos, a passar pelo processo de justificação con- versativa. É nessa diferença entre o sujeito autorreferenciado do liberalismo, e a concepção intersubjetiva do comunitarismo, que então divergem as formas de interpretar o espaço público.

Benhabib aposta que a ética discursiva de Habermas transcende essa dicotomia entre a vontade da maioria e as garantias constitucionais, ao colocar que "as condições normativas do discurso são, como os direitos e liberdades básicos, as regras do jogo que podem ser contestadas dentro do próprio jogo" 23 . Entretanto, ao que mostra o conflito atual da Grécia frente à União Europeia, essa dicotomia não se apresenta tão superada. Inclusive, podem-se observar, no artigo de Habermas sobre o tema, claros elementos de uma perspectiva comunitarista sobre o espaço público, distintos das visões individualistas do espaço agonístico e a da tradição liberal.

Arendt, provavelmente enxergaria nesse movimento europeu que Habermas cunhou de 'constituição de uma vontade política comum dos cidadãos' a perfeita ma-

\footnotetext{
22 Benhabib, 1992, p. 104, tradução nossa.

23 Benhabib, 1992, p. 107, tradução nossa.
} 
nifestação do espaço associativo, um renascimento de um nacionade que tanto sentia aversão. A lismo, dessa vez de esquerda, que questão atual da Grécia, por si só, viria a isolar a Grécia do continente já representaria o que tanto Arendt e gerar, talvez, um ambiente convicondenava na modernidade: a fic- dativo à 'ditadura da maioria'.

ção comunista. O problema da Grécia, que diz respeito à responsabilidade fiscal frente à zona do euro, não estaria no descompasso das finanças públicas, mas no fato de a associação entre os cidadãos gregos estar atrelada à economia, que deveria ser particular ao 'lar' da polis. A crise mostrou que, na Grécia de 2015, nada mais pertence ao indivíduo, o qual, inserido no modelo helênico antigo, equivaleria a um membro do lar, e não ao pater, que obtinha a liberdade de adentrar no espaço público ${ }^{24}$. Sob essa perspectiva, seria difícil conciliar a visão de Arendt com o entusiasmo de Habermas sobre uma possível penetração de alternativas políticas da comunidade grega atual na zona do euro. E, em relação à possibilidade de recusa às condições para a manutenção da Grécia na zona do euro, rejeição essa incentivada pelo Syriza, vê-se
Entretanto, sob a ótica liberal, a crítica viria a dizer respeito mais em relação ao falido Estado grego de bem-estar social, do que ao advento moderno do social que Arendt abordava em sua obra. Contudo, as duas críticas não estão desconectadas: Habermas pouco menciona a dívida do Estado grego, senão para apontar que ela é impagável. Interpretando as relações políticas na Grécia, a perspectiva liberal acusaria o déficit institucional de estabelecer normas que garantissem a responsabilidade fiscal, frente às vontades e objetivos individuais de cada cidadão. O imperativo da instituição supra-humana justamente remontaria a necessidade dos homens de serem enquadrados a normas racionais externas à sua vontade, concepção que permeou a escola liberal desde a sua fundação. Contrariamente, a política inclinada para

\footnotetext{
${ }^{24}$ Conforme Arendt, 2010, pp. 48-49: "A igualdade dos membros desses grupos, longe de ser uma igualdade entre pares, lembra antes de tudo a igualdade dos membros do lar ante o poder despótico do chefe do lar, exceto pelo fato de que, na sociedade, onde a força natural de um único interesse comum e de uma opinião unânime é tremendamente intensificada pelo puro número, o efetivo poder exercido por um único homem, representando o interesse comum e a opinião correta, podia mais cedo ou mais tarde ser dispensado".
} 
esquerda, que o governo grego vinha adotando e que, consequentemente, elevava o déficit público em relação ao PIB, cada vez mais aproximava os cidadãos de um Estado que, progressivamente, crescia de maneira irresponsável. Se preservada uma maior liberdade produtiva dos indivíduos frente ao Estado, eles não estariam todos no 'mesmo barco' e, tampouco, teriam um Estado tão inflacionado e devastador em sua crise.

Habermas atenta para o fato de que a população grega vem discutindo alternativas para a crise, porém não se atém ao fato de que grande parte da crise foi dada, justamente, por essa falta de autonomia dos cidadãos gregos frente ao mercado. A presença de elementos econômicos, como bancos, dívidas, empréstimos, e o dinheiro em si, enquanto instituições mediadoras das relações entre indivíduos em uma sociedade ordenada, como vê o liberalismo desde Locke, não tem essa conotação na perspectiva de Habermas, cuja significação da mediação monetária é atribuída a um subsistema imanente, porém não constitutivo do mundo da vida da Grécia, para não dizer da Europa em geral.
Dessa forma, a tecnocracia da representação na Europa, o vício das instituições, a elite credora e até mesmo o discurso nacionalista do Syriza, representam a colonização dos subsistemas no mundo da vida. É a partir disso que Habermas critica em seu artigo a 'comunidade monetária politicamente inacabada', ao mesmo tempo em que taxa a opinião pública de sonolenta, por ser espectadora de um jornalismo que "anda de mãos dadas com a classe política". O filósofo tem em mente, em sua crítica, o mundo da vida livre da colonização sistêmica, o que, para os liberais, não são dissociáveis. Habermas encerra, então, seu artigo, com a 'bola quicando' sobre o papel da opinião pública. Estaria o filósofo, nessa afirmação, condenando à visão liberal de razão pública, enquanto mero 'corpo investigativo parlamentar', como aponta Benhabib? É possível que sim, pois, no modelo da ética conversativa de Habermas, os indivíduos e a opinião pública têm um papel muito mais ativo na sociedade do que apenas o de fiscalizar a representação política. Se, então, essa representação política, valiosa desde Locke, porém falida para 
Habermas, concebe, para o último, a colonização nociva do mundo da vida pelos subsistemas da economia e da política, é melhor que se permita aos cidadãos europeus discutirem logo a solução para a crise. Caso contrário, como mostra a imagem escolhida por Habermas em seu artigo do Le Monde, faltará fígado para Prometeu.

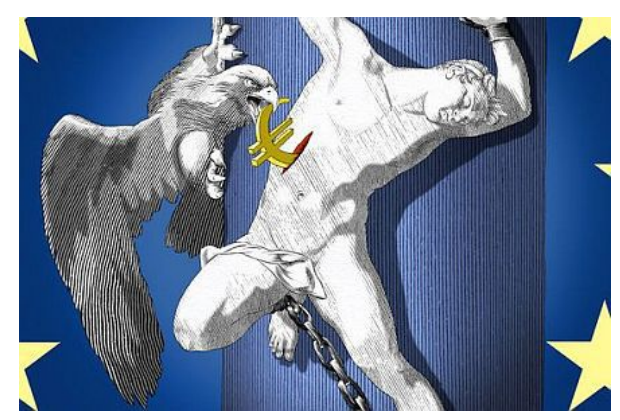

\section{Considerações Finais}

$\mathrm{O}$ artigo publicado por Habermas no Le Monde, em junho de 2015, mostrou-se oportuno no que diz respeito à crise pela qual passa a União Europeia, enquanto bloco político e econômico. Em meio à maré que acusa a Grécia como foco problemático, Habermas buscou, por outro lado, demonstrar que a crise, na realidade, é institucional e pertencente à Europa em sua totalidade. Para mostrar isso, Habermas interpreta a relação do povo grego com os repre- sentantes da União Europeia e com os credores das instituições financeiras, que, problematicamente, de acordo com o filósofo, se confundem.

O intuito deste trabalho, sobre a perspectiva habermasiana, foi demonstrar o quanto esse discurso sobre a crise europeia, que no momento ataca a Grécia, é permeado por conteúdos já presentes na Teoria do Agir Comunicativo que Habermas publicava em 1981. Assim, no decorrer do trabalho, essa perspectiva da ética conversativa foi comparada, por meio da crítica de Benhabib, aos modelos de espaço público de Arendt e da tradição liberal, a fim de demonstrar que diferentes concepções de espaço público poderiam produzir diferentes visões sobre problemas e soluções da crise política e econômica na Europa.

Assim, concluiu-se que os conceitos de mundo da vida e dos subsistemas, a ele imanentes, porém autopoiéticos, permearam o discurso de Habermas sobre a crise na Europa e em relação à polêmica acerca de seus rumos políticos em 2015. Devido a isso, tem-se no diagnóstico habermasiano a urgência de se preconizar a vontade popu- 
lar que busca se emancipar das ins- já tem feito. Habermas, assim, tituições tecnocráticas europeias. vê, na Europa, novas possibilidaPara o filósofo, essa vontade popu- des surgindo; atesta, portanto, que lar, imanentemente constituída, te- apenas os cidadãos europeus, entre ria o potencial de penetrar o conti- eles, poderão discuti-las e instituinente mais profundamente do que las.

\section{Referências bibliográficas}

ARENDT, H. A Condição Humana. $11^{a}$ edição. Rio de Janeiro: Forense Universitária, 2010.

BENHABIB, S. Situating the Self: Gender, Community and Postmodernism in Contemporary Ethics. New York: Routledge, 1992.

BIRD, M. "Absolutely everything you need to know about Greece's bailout crisis". In: Business Insider UK. Disponível em: <http://uk.businessi nsider.com/absolutely-everything-you-need-to-know-about-greecesbailout-crisis-2015-6>. Acesso em: 27/ 06/2015.

FORST, R. Contextos da Justiça. São Paulo: Ed. Boitempo, 2010.

HABERMAS, J. Teoria do Agir Comunicativo: 2. Sobre a crítica da razão funcionalista. São Paulo: Ed. WMF Martins Fontes, 2012. . "La scandaleuse politique grecque de l'Europe". In: Le Monde. Disponível em: <http://www.lemonde.fr/acces-restreint /idees/article/2015/06/24/6d6b6896666b68c595656763649871 _4660360_3232.html>. Acesso em 27/06/2015.

NYTIMES. “Greece's Debt Crisis Explained". In: The New York Times. Disponível em:<https://www.nytimes.com/interactive/2016/ business/international/greece-debt-crisis-euro.html $>$. Acesso em: 27/06/2015.

ROUSSEAU, J-J. Do Contrato Social. São Paulo: Ed. Abril Cultural, 1973. 